\title{
Silver Exsolution-Enhanced Electrical Properties of Lanthanum-Based Perovskites
}

\author{
Rokas Sažinas and Kent Kammer Hansen \\ Department of Energy Conversion and Storage, Technical University of Denmark, Roskilde DK-4000, Denmark
}

\begin{abstract}
The effect of silver (Ag) exsolution on the electrical conductivity of strontium-doped lanthanum manganite $\left(\mathrm{La}_{1-x-y} \mathrm{Sr}_{x} \mathrm{Ag}_{y} \mathrm{MnO}_{3-\delta}, \mathrm{LSAM}\right)$ and ferrite $\left(\mathrm{La}_{1-x-y} \mathrm{Sr}_{x} \mathrm{Ag}_{y} \mathrm{FeO}_{3-\delta}, \mathrm{LSAF}\right)$ perovskites was investigated. The single-phase Ag-doped materials formed at $800{ }^{\circ} \mathrm{C}$ using modified Pechini method and revealed thermal stability in oxidizing atmosphere up to sintering temperature of the materials at $1,200{ }^{\circ} \mathrm{C}$. The exsolution of the metallic Ag nanoparticles was performed at $420-500{ }^{\circ} \mathrm{C}$ in reducing atmosphere of $5 \% \mathrm{H}_{2} / \mathrm{N}_{2}$. Scanning electron microcopy results exhibited the metallic Ag phase nanoparticles on the surface of the oxide backbone with a good contact of $\mathrm{Ag}$ to the surface of the perovskite after exsolution. The electrical conductivity of the materials was investigated in the temperature range of $50-900{ }^{\circ} \mathrm{C}$ in air and isothermally in $5 \% \mathrm{H}_{2} / \mathrm{N}_{2}$ at 420 and $500{ }^{\circ} \mathrm{C}$ by means of four probe DC measurement method, and reached 80-230 S.cm ${ }^{-1}$ for undoped and Ag-doped LSF and LSM. The electrical conductivity results showed improving conductivity in Ag-doped single-phase and Ag nanoparticle decorated perovskites after Ag exsolution. The results revealed the dependence of electrical conductivity on the atmosphere, temperature and Ag exsolution time.
\end{abstract}

Key words: Silver nanoparticles, exsolution, SOFC, cathodes, LSM, LSF, ceramics.

\section{Introduction}

Lanthanum-based perovskite oxides, $\mathrm{La}(\mathrm{III}) \mathrm{M}(\mathrm{III}) \mathrm{O}_{3}$, are state-of-the-art materials for electrodes in solid state electrochemical devices and have received much attention due to their outstanding properties, such as high electrical conductivity, fast surface oxygen exchange, easy oxygen ion diffusion and thermal stability $[1,2]$. The modified perovskite oxides with metal nanoparticles on the surface have been widely studied as catalytic materials in few chemical and electrochemical processes, such as solid oxide fuel cells (SOFCs) [3, 4], electrolyzers (SOECs) [5], and automotive emission control [2, 6, 7]. The increased surface area of the oxides with metal nanoparticles enhances the overall catalytic activity by providing a large amount of active sites on the surface and potential synergistic effects on the interface between the metal and oxide phases $[8,9]$. The

Corresponding author: Rokas Sažinas, Dr., research fields: SOFC, cathodes, exsolution, silver chemistry, wet chemistry, ceramics, lanthanum manganite, lanthanum ferrite, electrical conductivity. material performance has been improved by decorating precious metal nanoparticles on the oxide surface as active catalysts through a chemical deposition process such as infiltration or electrodeposition [2, 10]. However, the deposited nanoparticles often distribute closely and aggregate easily at high temperatures, leading the nanoparticle coarsening to irreversible performance degradation $[10,11]$. In addition, the effective deposition by infiltration requires time due to several depositions needed. Most of these disadvantages of the infiltration and electrode position methods can be overcome by the exsolution process.

Exsolution of metal or oxide nanoparticles from single phase perovskite precursors has received much attention as alternative improvement of the electrodes for SOFCs because of their highly dispersed distribution on the oxide surface with a size of tens of nanometers $[11,12]$. The exsolution based on in situ growth of metal nanoparticles from the parent perovskite is an attractive approach for designing nanoparticle-supported perovskite materials. The 
exsolution phenomenon involves the in situ diffusion and reduction of the specific perovskite cations on the oxide surface under reducing conditions and avoids the time-consuming process and expensive precursors of the traditional infiltration process $[9,13]$. The cation precipitation as metal is directed by the intrinsic reducibility of the metal oxide and the nonstoichiometry of the perovskite oxide [13]. The easily reducible precious metals, such as $\mathrm{Rh}, \mathrm{Pt}, \mathrm{Pd}$, $\mathrm{Ru}$, and $\mathrm{Ag}$ on the $\mathrm{A}$-site, and some first-row transition metals $(\mathrm{Fe}, \mathrm{Co}$, and $\mathrm{Ni})$ on the $\mathrm{B}$-site can be incorporated in $\mathrm{A}(\mathrm{III} ; \mathrm{II}) \mathrm{B}(\mathrm{III} ; \mathrm{IV}) \mathrm{O}_{3}$ perovskite during material synthesis in air, followed by the metal exsolution from the perovskite backbone as highly dispersed nanoparticles under reducing atmosphere [2, 14]. As a result, the material's performance is greatly improved by the exsolved nanocatalysts [11]. According to several recent reports, well-defined nanoparticle-supported perovskites have been obtained showing the embedded nanoparticles on the surface of the perovskite after exsolution, what prevents agglomeration and coarsening of the nanoparticles during operation [11]. Recently, we have shown that exsolution of $\mathrm{Ag}$ from $\mathrm{La}_{1-x-y} \mathrm{Sr}_{x} \mathrm{Ag}_{y} \mathrm{MnO}_{3-\delta}$ (LSAM) materials enhances the electrochemical properties of the cathodes for solid oxide fuel cells [14]. The trends in Ag exsolution from the perovskites and its mechanism have been discussed. To the best of our knowledge, there have been no thorough studies on the effect of $\mathrm{Ag}$ exsolution on electrical conductivity in time and different reducing/oxidizing atmospheres. Therefore, exsolution trends in the redox stable perovskites of particular interest can provide a strategy of tailoring materials for electrocatalytic application, such as solid oxide cell electrodes, catalytic oxidation of hydrocarbons and thermochemical hydrogen production from water.

In this experimental study, we report the effect of $\mathrm{Ag}$ exsolution on electrical conductivity in $\mathrm{La}_{1-x-y} \mathrm{Sr}_{x} \mathrm{Ag}_{y} \mathrm{MnO}_{3-\delta}$ (LSAM) and $\mathrm{La}_{1-x-y} \mathrm{Sr}_{x} \mathrm{Ag}_{y} \mathrm{FeO}_{3-\delta}$
(LSAF) perovskites. The single phase Ag-doped materials were synthesized by modified Pechini method followed by exsolution of metallic $\mathrm{Ag}$ and evaluated in detail by 4-point DC measurements. An enhancement of electrical conductivity after exsolution of $\mathrm{Ag}$ in reducing atmosphere was determined and the dependence of the electrical conductivity on $\mathrm{Ag}$ exsolution time was for the first time shown. The materials exhibited good chemical stability under reducing and oxidizing atmosphere, as well as competitive electrical conductivity in air and $5 \% \mathrm{H}_{2} / \mathrm{Ar}$. The effect of exsoluted $\mathrm{Ag}$ on the electrical performance of the materials was proved by comparison of the results on Ag-undoped lanthanum-perovskites. The electrical conductivity increased with exsolution temperature and time. The materials were characterized by X-ray powder diffraction (XRD), thermal gravimetric analysis (TGA), dilatometry, scanning electron microscopy (SEM) and energy dispersive X-ray spectroscopy (EDS).

\section{Experimental}

\subsection{Synthesis of the Materials}

The materials with the nominal composition $\mathrm{La}_{0.85} \mathrm{Sr}_{0.15} \mathrm{MnO}_{3-\delta}$ (LSM), $\mathrm{La}_{0.85} \mathrm{Sr}_{0.15} \mathrm{FeO}_{3-\delta}$ (LSF), $\mathrm{La}_{0.8} \mathrm{Sr}_{0.15} \mathrm{Ag}_{0.05} \mathrm{MnO}_{3-\delta} \quad$ (LSAM) and $\mathrm{La}_{0.8} \mathrm{Sr}_{0.15} \mathrm{Ag}_{0.05} \mathrm{FeO}_{3-\delta}$ (LSAF), where $x=0-0.05$, were prepared by modified Pechini methods. The detailed synthesis route and characterization of LSM and LSAM materials is described elsewhere [14]. For synthesis of LSAF, the stoichiometric amount of metal precursors, as $\mathrm{AgNO}_{3}, \quad \mathrm{La}\left(\mathrm{NO}_{3}\right)_{3} \cdot 6 \mathrm{H}_{2} \mathrm{O}$, $\mathrm{Sr}\left(\mathrm{NO}_{3}\right)_{2}$ and $\mathrm{Fe}\left(\mathrm{NO}_{3}\right)_{3} \cdot 9 \mathrm{H}_{2} \mathrm{O}$ (Sigma Aldrich and Merck, Germany; quality: $>99.9 \%$ analytical pure) was dissolved in deionized water followed by the addition of citric acid (CA, Sigma Aldrich). The solution with $\mathrm{pH} \sim 1$ was mixed for a while and butane-1,4-diol (BD, Sigma Aldrich) was added until completely mixed. The molar amount ratio of total metal ions, CA and BD was optimized to be 1:1.5:6. 
The solution was stirred at ambient temperature for 1 $\mathrm{h}$ with the following temperature increase to $90^{\circ} \mathrm{C}$ for the solvent to evaporate until the gelation started. The gel was precalcined at $250^{\circ} \mathrm{C}$ for $5 \mathrm{~h}$ and afterwards fired at $800{ }^{\circ} \mathrm{C}$ for $5 \mathrm{~h}$ to combust all organic compounds, to decompose the nitrate ions and to obtain the main phase of the materials. The dark black powders were produced, which were further grinded in an agate mortar. The ex situ exsolution of $\mathrm{Ag}$ nanoparticles in LSAM and LSAF was performed in a tube furnace at $420{ }^{\circ} \mathrm{C}$ in $50 \mathrm{~mL} / \mathrm{min}$ flow of $5 \%$ $\mathrm{H}_{2} / \mathrm{N}_{2}$.

\subsection{Materials Characterization}

The phase purity of the powders was confirmed by powder XRD using a Bruker D8 diffractometer (USA) with filtered $\mathrm{CuK}_{\alpha 1}$ irradiation at $40 \mathrm{kV}$ and $44 \mathrm{~mA}$. The diffraction patterns were collected at room temperature by step scanning in the range of $15 \leq 2 \theta \leq$ $90^{\circ}$ with a scan rate of $0.6-2^{\circ} \mathrm{min}^{-1}$. The Rietveld refinement was performed with Winpow software (DTU Chemistry, Denmark) using an orthorhombic structure model Pbnm (No. 62) for the perovskite and a cubic structure model Fm $\overline{3} \mathrm{~m}$ (No.225) for Ag. Initially, refinements were performed varying global parameters such as lattice and peak shape parameters, background, phase fractions and sample displacement correction. Finally, fitting of the fractional occupancy and isotropic atomic displacement factors (ADFs) was also done. SEM imaging and EDS elemental analysis were carried out with TM3000, Carl Zeiss Merlin and Carl Zeiss Ultra field emission scanning electron microscopes (Germany) in secondary electron (SE) and back-scattered electron (BSE) modes. The InLens, HE-S2 and AsB detectors were used in the Zeiss electron microscopes.

\subsection{Electrical Conductivity Measurements}

The bars for conductivity studies were made by pressing the powders in the appropriate dies with 1 drop/g powder of $9 \%$ polyvinylpyrrolidone (PVP) solution in ethanol as a binder. The bars were sintered at $1,200{ }^{\circ} \mathrm{C}$ for $5 \mathrm{~h}$ with $120^{\circ} \mathrm{C} / \mathrm{h}$ heating and cooling rates in a chamber furnace in air. The ceramics resulted in $>95 \%$ densities according to the Archimedes method in isopropanol at room temperature. After sintering, the bars were machined into smaller bars with the approximate size of $4 \times 4 \times$ $18 \mathrm{~mm}^{3}$. The XRD measurements were also performed on the bars.

The dilatometry measurements on the machined bars were conducted using a Netzsch 402 dilatometer in the temperature range $30-1,000{ }^{\circ} \mathrm{C}$. The heating and cooling ramps were $2{ }^{\circ} \mathrm{C} / \mathrm{min}$. The samples were kept at $1,200{ }^{\circ} \mathrm{C}$ for $2 \mathrm{~h}$ before cooling to see the possible structural isothermal changes of the materials.

The DC electrical conductivity was measured in a 4-point probe arrangement with micro-ohmmeter (Keithley 580) in a homemade setup shown elsewhere [15]. The platinum $(\mathrm{Pt})$ wires were attached to the ends of the bars and painted with Pt paste for a good contact of the Pt wire with the bar. Two potential probes (Pt wires) with a fixed distance of $0.75 \mathrm{~cm}$ were set on one side of the bar with a spring load. The electrical conductivity was measured from at 50-900 ${ }^{\circ} \mathrm{C}$ with increments of $50{ }^{\circ} \mathrm{C}$ with a thermocouple located next to the sample and in synthetic air of $20 \% \mathrm{O}_{2} / \mathrm{N}_{2}$. The isothermal electrical conductivity measurements were performed separately at 420 and $500{ }^{\circ} \mathrm{C}$ in $5 \% \mathrm{H}_{2} / \mathrm{N}_{2}$. The conductivity values were corrected for the porosity of the samples described elsewhere [16].

\section{Results}

The LSF, LSM, LSAF and LSAM materials were synthesized by wet chemical synthesis route and subjected to the exsolution of $\mathrm{Ag}$ nanoparticles in reducing atmosphere. The phase pure orthorhombic Ag-doped perovskites with a space group $\mathrm{Pbnm}(\mathrm{Nr}$. 62) were obtained after firing at $800{ }^{\circ} \mathrm{C}$ in air as shown for LSAF and LSAM in Figs. $1 \mathrm{a}$ and $1 \mathrm{~b}$, respectively. The shift of peak positions of the 
orthorhombic LSAF phase is highlighted in Fig. 1. The XRD results in Fig. 1 and Table 1 indicate that the Ag-doping induces expansion of the lattice according to the increase in cell parameters and cell volume, respectively. Fig. 1 also shows the XRD results for the exsolution of $\mathrm{Ag}$ nanoparticles from LSAF perovskite material. It can be seen that the characteristic peaks of cubic Ag (ICDD card $00-001-1164)$ at $38.13(100 \%), 44.28(52 \%)$ and 64.43 $(36 \%)$ are visible after heat treatment of LSAF and LSAM materials at $420{ }^{\circ} \mathrm{C}$ for $5 \mathrm{~h}$ in $5 \% \mathrm{H}_{2} / \mathrm{N}_{2}$. The reduction of the LSAF material induces the shift of the XRD peak positions back to higher $2 \theta$ angles. The lattice parameter of the cubic Ag structure was found $\sim 4.1 \AA$.

The microstructure of LSAF powder is shown in Fig. 2a. The particle size of the materials after firing at $800{ }^{\circ} \mathrm{C}$ for $5 \mathrm{~h}$ in air was found below $100 \mathrm{~nm}$ by linear intercept method. Most of the particles are round-shaped. The microstructure of sintered LSAF material after ex situ exsolution of Ag nanoparticles at $420{ }^{\circ} \mathrm{C}$ for $5 \mathrm{~h}$ in $5 \% \mathrm{H}_{2} / \mathrm{N}_{2}$ is shown in Fig. 2b. Small $\mathrm{Ag}$ nanoparticles with different size are formed on the surface of the perovskite. The Ag nanoparticle size was determined below $30 \mathrm{~nm}$ (assuming round-shape) with a location mainly on the grain boundaries of the perovskite backbone with the average particle distribution of $\sim 5.3$ particles $\mathrm{cm}^{-2}$. Fig. $2 \mathrm{c}$ shows EDS line scan results from SEM measurements. The distinct nanosized Ag-rich regions or particles can be seen on the surface of the materials. The microstructural characterization of LSM and LSAM materials is described in detail elsewhere [14].

The TGA results for the LSAF material in air and $5 \% \mathrm{H}_{2} / \mathrm{N}_{2}$ up to temperature of $1,100{ }^{\circ} \mathrm{C}$ with a heating/cooling ramp rate of $5^{\circ} \mathrm{C} \mathrm{min}^{-1}$ are shown in Fig. 3. No considerable mass loss is observed heating and cooling the material in air and Ar in contrary to
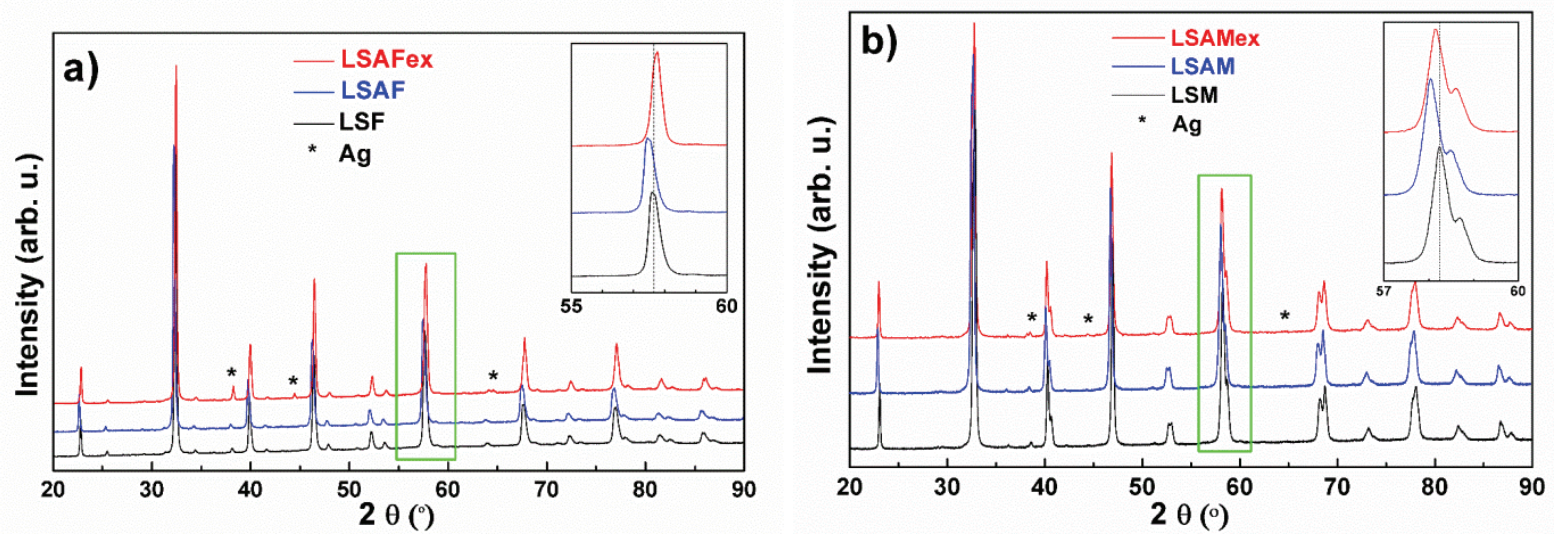

Fig. 1 Powder XRD patterns of undoped (LSF; LSM) and Ag-doped lanthanum perovskites before (LSAF; LSAM) and after (LSAFex; LSAMex) exsolution of the Ag nanoparticles at $420{ }^{\circ} \mathrm{C}$ for $5 \mathrm{~h}$ in $5 \% \mathrm{H}_{2} / \mathrm{N}_{2}$.

Table 1 The results for Rietveld refinement and dilatometry of the materials.

\begin{tabular}{llllllll}
\hline & \multicolumn{7}{c}{ Cell parameters $(\AA)$} \\
\cline { 2 - 8 } Material & \multicolumn{7}{c}{ Perovskite (Pbnm, No. 62) } \\
\cline { 2 - 8 } & $\mathrm{a}$ & $\mathrm{b}$ & $\mathrm{c}$ & $\begin{array}{l}\text { Volume } \\
\left(\AA^{3}\right)\end{array}$ & $\begin{array}{l}\text { Density } \\
\left(\mathrm{g} \cdot \mathrm{cm}^{-3}\right)\end{array}$ & $\begin{array}{l}\text { Relative density } \\
(\%)\end{array}$ & $\begin{array}{l}\text { TEC }\left(10^{-6},\right. \\
\left.\mathrm{K}^{-1}\right)\end{array}$ \\
\hline LSF & $5.511 \pm 0.001$ & $5.537 \pm 0.001$ & $7.831 \pm 0.002$ & $238.99 \pm 0.12$ & 6.532 & 95 & 11.3 \\
LSAF & $5.530 \pm 0.002$ & $5.557 \pm 0.002$ & $7.860 \pm 0.003$ & $241.58 \pm 0.21$ & 6.462 & 96 & 11.5 \\
LSAFex & $5.525 \pm 0.001$ & $5.517 \pm 0.002$ & $7.811 \pm 0.002$ & $238.09 \pm 0.13$ & 6.513 & 96 & 12.2 \\
LSM & $5.516 \pm 0.001$ & $5.459 \pm 0.001$ & $7.747 \pm 0.002$ & $233.28 \pm 0.09$ & 6.666 & 95 & 11.8 \\
LSAM & $5.531 \pm 0.001$ & $5.508 \pm 0.001$ & $7.852 \pm 0.002$ & $239.24 \pm 0.06$ & 6.307 & 97 & 11.6 \\
LSAMex & $5.517 \pm 0.001$ & $5.464 \pm 0.001$ & $7.753 \pm 0.001$ & $233.75 \pm 0.05$ & 6.608 & 95 & 12.0 \\
\hline
\end{tabular}



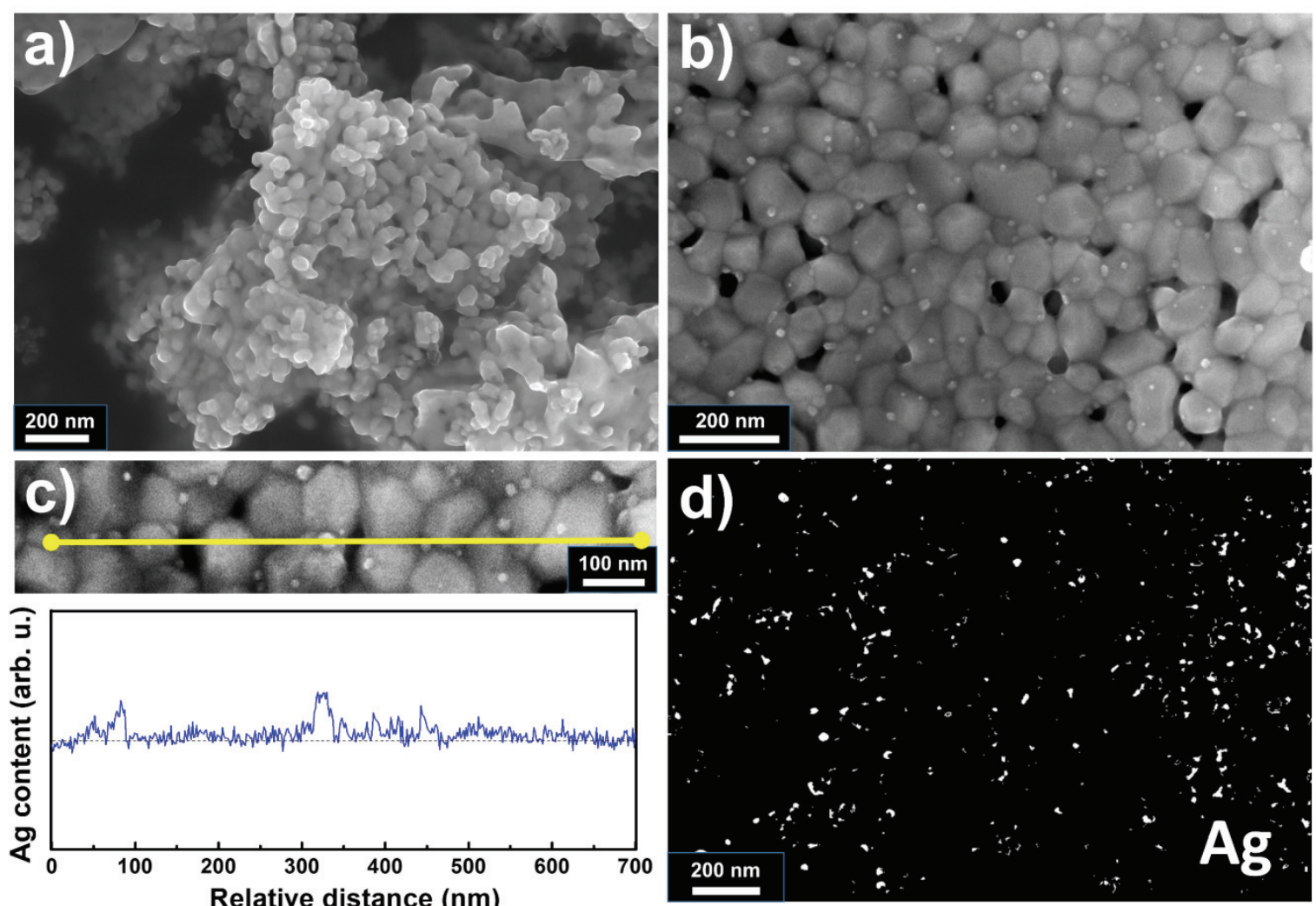

Fig. 2 SEM micrographs of (a) LSAF as-synthesized powder; (b) LSAF bar after heat treatment at $420{ }^{\circ} \mathrm{C}$ for $5 \mathrm{~h}$ in $5 \%$ $\mathrm{H}_{2} / \mathrm{N}_{2}$; and (c) EDS line scan and (d) EDS map of Ag-rich regions in LSAFex after exsolution of Ag.

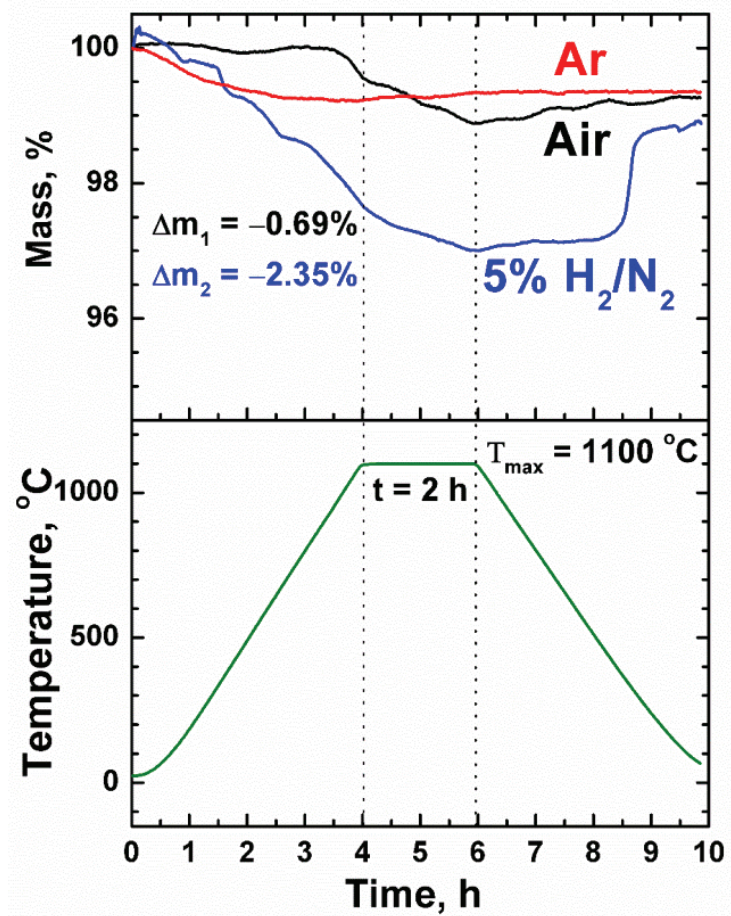

Fig. 3 TGA results for the LSAF material in Ar, air and $5 \% \mathrm{H}_{2} / \mathrm{N}_{2}$ upon heating to $1,100{ }^{\circ} \mathrm{C}$, dwelling for $2 \mathrm{~h}$ and cooling to room temperature with the ramp rate of $5^{\circ} \mathrm{C} / \mathrm{min}$. 
reducing atmosphere. According to the results, the LSAF material loses $\sim 2.3 \%$ of the weight which could be attributed to the evaporation of $\mathrm{Ag}$ in reducing atmosphere above $\sim 500{ }^{\circ} \mathrm{C}$. The drastic mass increase of the LSAF material on cooling is attributed to the reaction of $\mathrm{Pt}$ wire in TGA equipment with $\mathrm{H}_{2}$. In general, the main mass losses in reducing atmosphere could be attributed to the oxygen loss and water molecule formation due to $\mathrm{Fe}(\mathrm{IV}) / \mathrm{Fe}$ (III) which is supported by the XRD after TG analysis. The thermogravimetric analysis of LSAM material is described in detail elsewhere [14].

Fig. 4 represents Arrhenius-type plots as logarithmic DC electrical conductivities versus inverse temperature for LSF, LSAF, LSAFex, LSM,

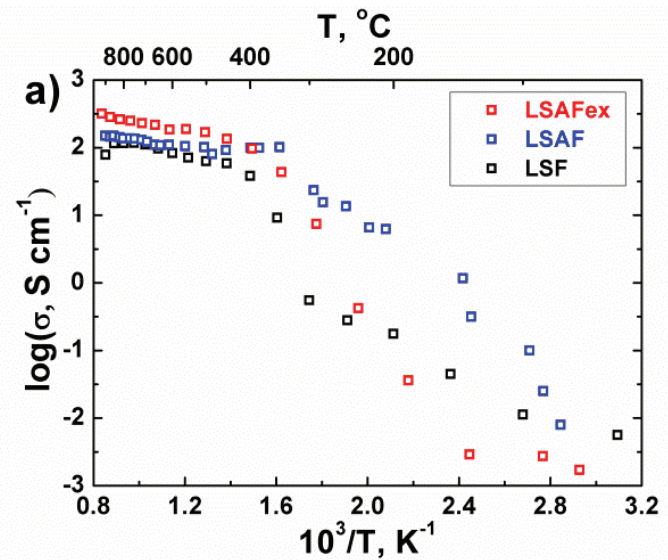

LSAM and LSAMex materials measured at $50-900{ }^{\circ} \mathrm{C}$ in air. The results of fitting the Arrhenius plots are summarized in Table 2. It is notable that in Fig. 4a, two different regions exist for LSF, LSAF and LSAFex perovskites with different activation energies below and above $400{ }^{\circ} \mathrm{C}$. At temperatures higher than $400{ }^{\circ} \mathrm{C}$, the conductivity values increase as follows LSF $<$ LSAF $<$ LSAFex. LSM, LSAM and LSAMex materials have similar activation energies in both regions. The conductivity values of the materials at $800{ }^{\circ} \mathrm{C}$ in air are compared in Table 3. Both the Ag-doping and exsolution in lanthanum-based perovskite enhance electrical conductivity of the materials. LSF-based materials reveal higher electrical conductivity than LSM.

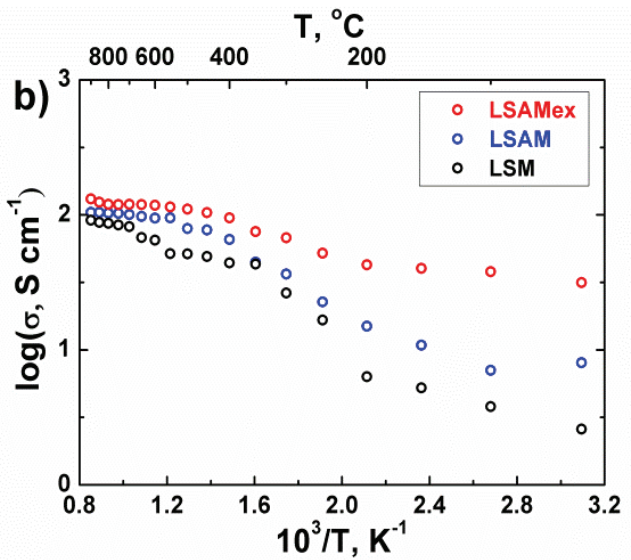

Fig. 4 Arrhenius-type plots of DC logarithmic electrical conductivity values for (a) LSF, LSAF and LSAFex and (b) LSM, LSAM and LSAMex materials measured at 50-900 ${ }^{\circ} \mathrm{C}$ in air.

Table 2 The activation energies (eV) of the undoped and Ag-doped LSF and LSM materials from Arrhenius plots in air before and after exsolution in $5 \% \mathrm{H}_{2} / \mathrm{N}_{2}$.

\begin{tabular}{|c|c|c|c|c|c|c|}
\hline \multirow{2}{*}{ Region } & \multicolumn{6}{|c|}{ Material } \\
\hline & LSF & LSAF & LSAFex & LSM & LSAM & LSAMex \\
\hline$>400^{\circ} \mathrm{C}$ & $0.13 \pm 0.03$ & $0.13 \pm 0.01$ & $0.17 \pm 0.02$ & $010+002$ & $018+002$ & $015+003$ \\
\hline$<400{ }^{\circ} \mathrm{C}$ & $0.55 \pm 0.10$ & $0.62 \pm 0.04$ & $0.76 \pm 0.16$ & $0.19 \pm 0.02$ & $0.10 \pm 0.02$ & $0.13 \pm 0.05$ \\
\hline
\end{tabular}

Table 3 The electrical conductivity values of the materials at $800{ }^{\circ} \mathrm{C}$ in air before and after exsolution in $5 \% \mathrm{H}_{2} / \mathbf{N}_{2}$.

\begin{tabular}{ll}
\hline Material & $\sigma\left(\mathrm{S} \cdot \mathrm{cm}^{-1}\right)$ \\
\hline LSF & 117 \\
LSAF & 138 \\
LSAFex & 227 \\
LSM & 85 \\
LSAM & 103 \\
LSAMex & 114 \\
\hline
\end{tabular}


The Arrhenius-type plot for LSAFex after exsolution at $420{ }^{\circ} \mathrm{C}$ for $5 \mathrm{~h}$ in $5 \% \mathrm{H}_{2} / \mathrm{N}_{2}$ measured at 50-900 ${ }^{\circ} \mathrm{C}$ in air is represented in Fig. 5. The linear fitting results of natural logarithm of DC electrical conductivity multiplied by absolute temperature are shown as red lines. The activation energy increases in the materials after Ag exsolution. Two distinct regions below and above $400{ }^{\circ} \mathrm{C}$ are present giving the activation energy values of 0.70 and $0.21 \mathrm{eV}$ in Fig. 5, respectively. The fitting results as activation energies of the two regions for all the materials are summarized in Table 2.

The dependence of DC electrical conductivity on Ag exsolution time in LSAF material measured in 5\% $\mathrm{H}_{2} / \mathrm{N}_{2}$ is summarized in Fig. 6. Fig. 6a reveals the exsolution process as a function of time with experimental conditions at $420{ }^{\circ} \mathrm{C}$. The electrical conductivity increase can be seen when the gases are changed from air to $5 \% \mathrm{H}_{2} / \mathrm{N}_{2}$ at $420{ }^{\circ} \mathrm{C}$. The effect of Ag exsolution on electrical conductivity as a function of time and temperature in $5 \% \mathrm{H}_{2} / \mathrm{N}_{2}$ for LSAF and LSAM materials is shown in Fig. 6b. Increasing the exsolution temperature and time, the DC conductivity values of the materials increase. LSAF materials have higher electrical conductivity compared to LSAM materials which are given in Table 3. Fig. 6c shows magnified dependence of logarithmic conductivity on exsolution time at $500{ }^{\circ} \mathrm{C}$. At these conditions, the conductivity increases in $10 \mathrm{~h}$ with the following decrease later in 5-10 $\mathrm{h}$ and subsequent increase in the rest of the time. Fig. $6 \mathrm{~d}$ represents the dependence of DC electrical conductivity on $\mathrm{Ag}$ exsolution time in LSAF material measured in $5 \% \mathrm{H}_{2} / \mathrm{N}_{2}$ at $420{ }^{\circ} \mathrm{C}$. The exponential fitting according to the equation given in the Fig. $6 \mathrm{~d}$ is shown as a red line and the results are summarized in Table 4.

The XRD with Rietveld refinement results and microstructure of the LSAF bar after conductivity measurements at $50-900{ }^{\circ} \mathrm{C}$ in air followed by $5 \%$ $\mathrm{H}_{2} / \mathrm{N}_{2}$ at $420{ }^{\circ} \mathrm{C}$ is shown in Fig. 7. According to XRD diffractogram, there are no secondary phases in the materials except exsoluted Ag (Fig. 7a) and it can be concluded that the orthorhombic phase (Pbnm) of the perovskite after conductivity tests may not be affected

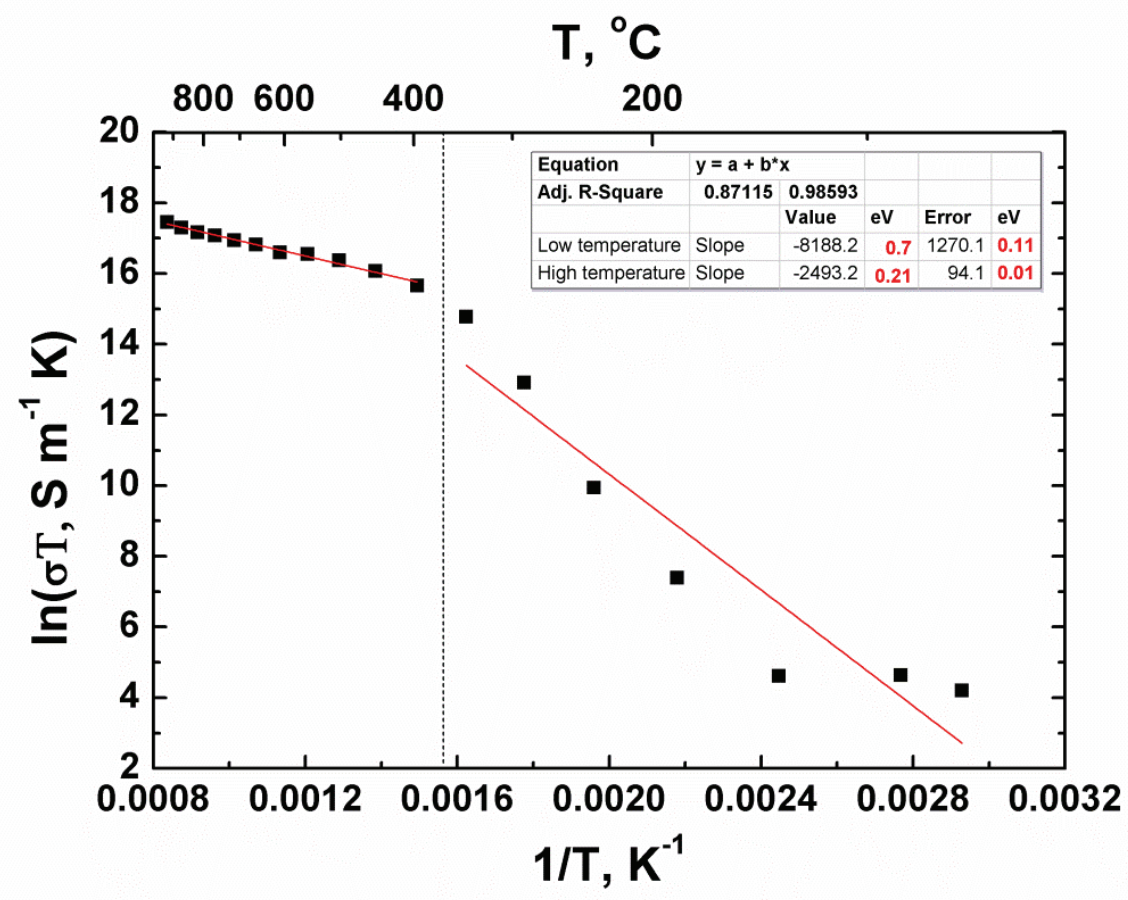

Fig. 5 Arrhenius-type plot with fitting results (red lines) of DC electrical conductivity for LSAFex after exsolution at $420{ }^{\circ} \mathrm{C}$ in $5 \% \mathrm{H}_{2} / \mathrm{N}_{2}$ measured at $50-900{ }^{\circ} \mathrm{C}$ in air. 

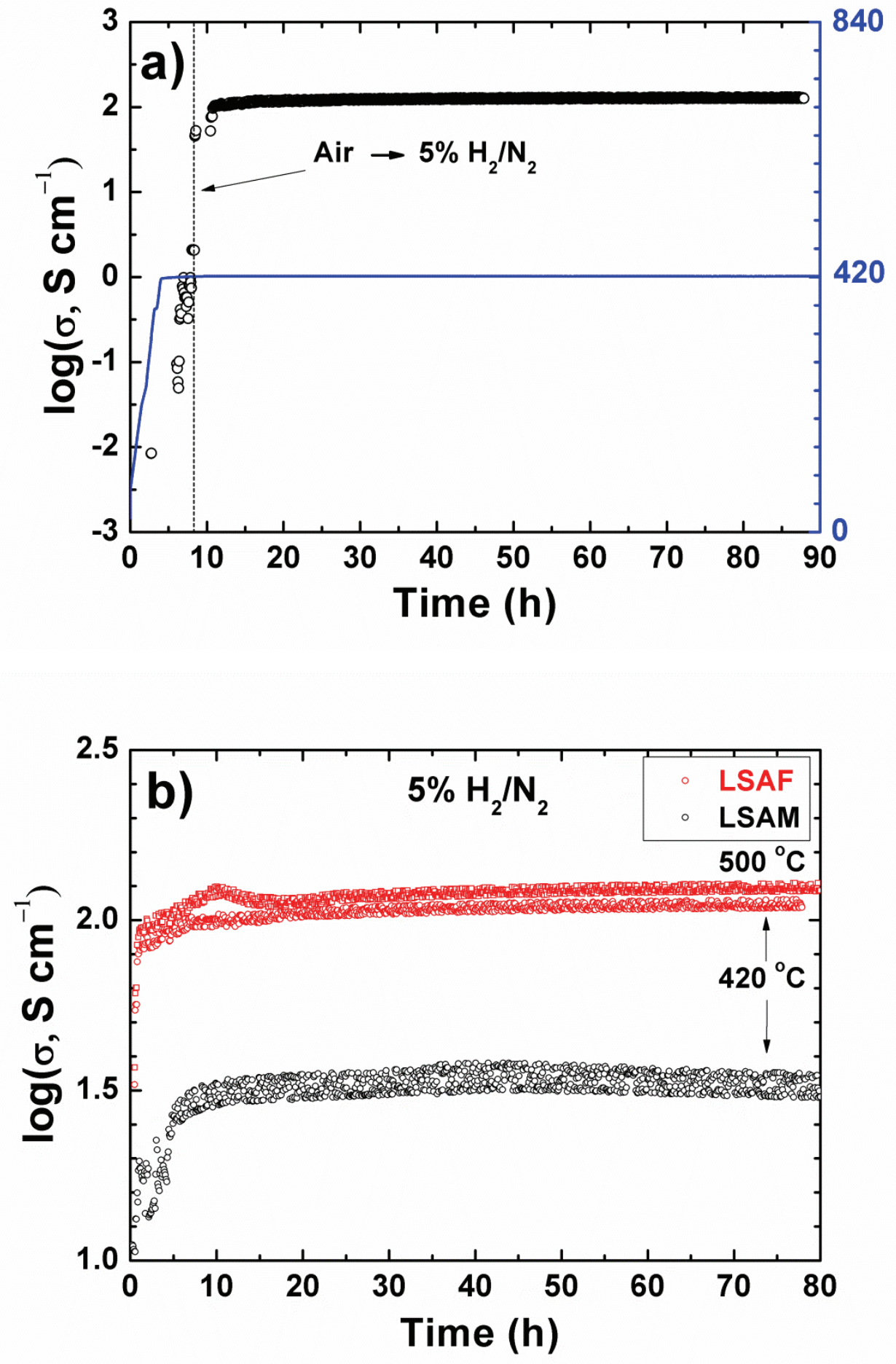

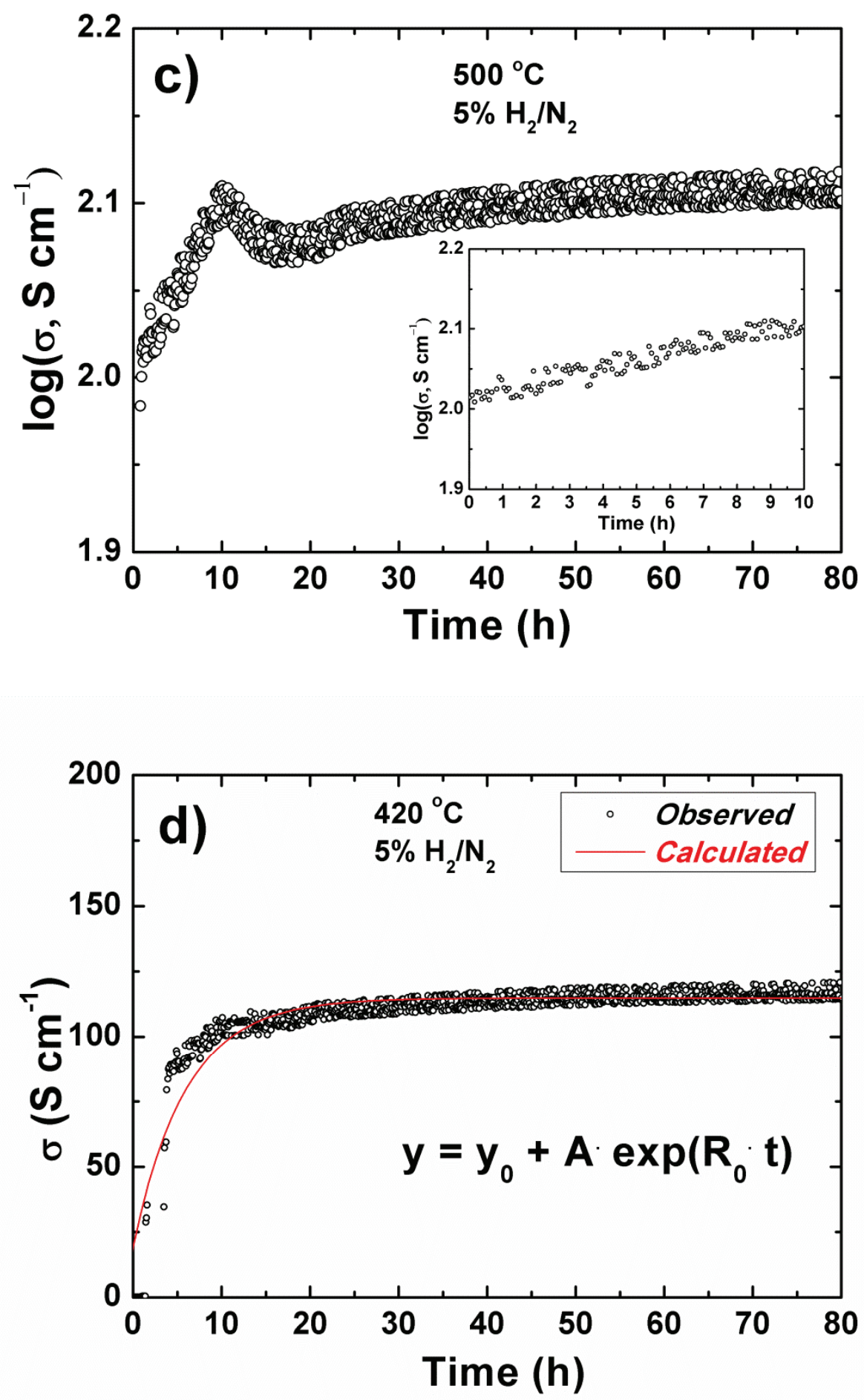

Fig. 6 Experimental results for DC electrical conductivity of Ag exsolution in the materials measured in $5 \% \mathrm{H}_{2} / \mathrm{N}_{2}$ : (a) experimental conditions at $420{ }^{\circ} \mathrm{C}$; (b) the dependence of logarithmic conductivity on exsolution time at different temperatures for LSAF and LSAM materials; (c) the dependence of logarithmic conductivity on exsolution time for LSAF material at $500{ }^{\circ} \mathrm{C}$; (d) the dependence of DC electrical conductivity on Ag exsolution time in LSAF material measured in $5 \%$ $\mathrm{H}_{2} / \mathrm{N}_{2}$ at $420{ }^{\circ} \mathrm{C}$ with exponential fitting shown as a red line and summarized in Table 4. 
Table 4 The results for fitting the dependence of electrical conductivity as a function of time at $420{ }^{\circ} \mathrm{C}$ in $5 \% \mathrm{H}_{2} / \mathrm{N}_{2}$.

\begin{tabular}{lll}
\hline Equation & $y=y_{0}+A \cdot \exp \left(R_{0} \cdot t\right)$ & \\
\hline$R^{2}$ & 0.89 & Error \\
\hline Parameter & Value & 0.2 \\
$y_{0}$ & 114.9 & 7.4 \\
$A$ & -97.7 & 0.003 \\
$R_{0}$ & -0.167 & \\
\hline
\end{tabular}
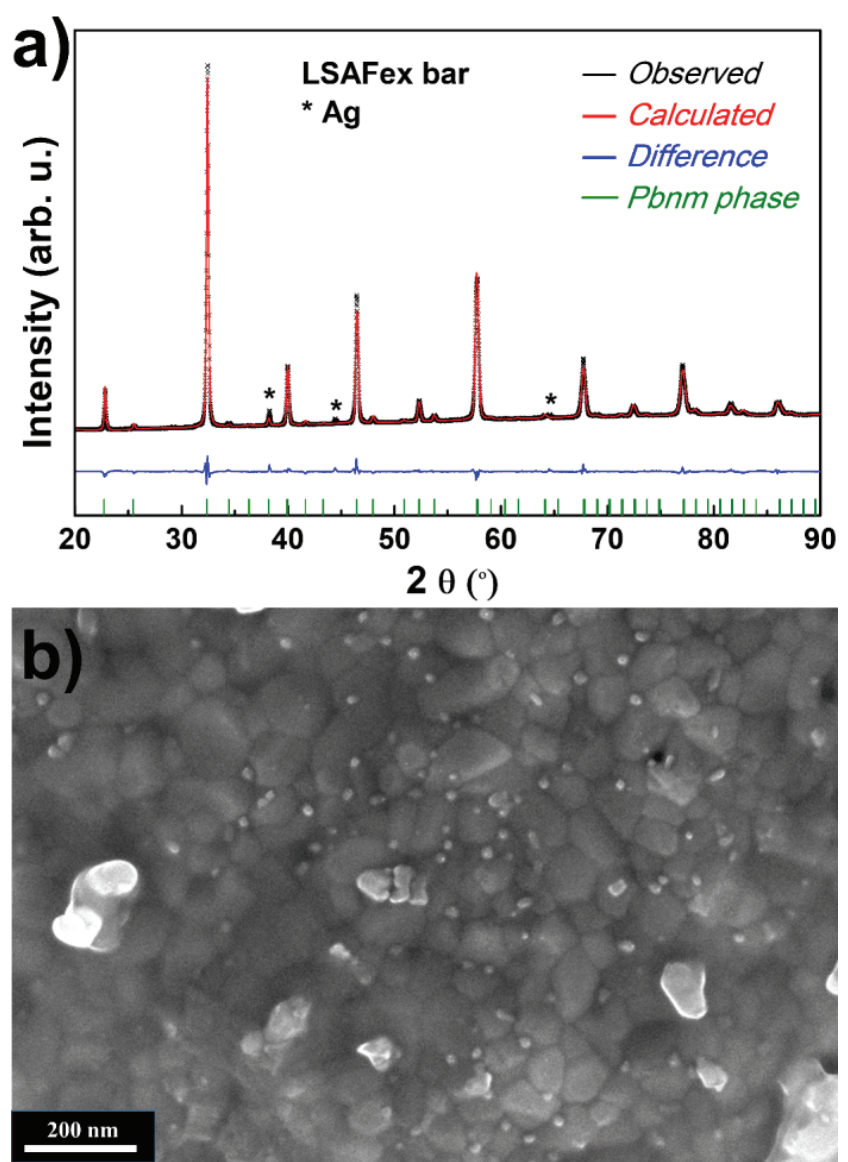

Fig. 7 (a) XRD diffractogram and (b) SEM micrograph of the LSAF bar after DC conductivity measurements in air and 5\% $\mathrm{H}_{2} / \mathrm{N}_{2}$ at $420^{\circ} \mathrm{C}$.

by the reducing atmosphere up to $420{ }^{\circ} \mathrm{C}$. The SEM micrograph (Fig. 7b) of the LSAF bar after DC conductivity measurement shows nanoscaled Ag nanoparticles exsoluted from the main perovskite lattice. The size of the $\mathrm{Ag}$ nanoparticles $(<30 \mathrm{~nm})$ reveals no agglomeration and stability of the particles after DC conductivity tests at $50-900{ }^{\circ} \mathrm{C}$ in air and $420{ }^{\circ} \mathrm{C}$ in reducing atmosphere of $5 \% \mathrm{H}_{2} / \mathrm{N}_{2}$.

\section{Discussion}

The exsolution of silver (Ag) nanoparticles from the lanthanum ferrite or manganite perovskite lattice, $\mathrm{La}$ (III)M(III) $\mathrm{O}_{3}$, enhances electrical conductivity of the materials as revealed in Figs. 4 and 6. Here we show for the first time the influence of A-site Ag metal exsolution from the perovskite lattice on the electrical conductivity of the materials in time. The obtained results and the mechanisms can be explained by the defect equilibria in the following way. It is suggested that the defect equilibria of the Ag exsolution explaining the increased conductivity of the materials could be described as follows in the reactions (1) and (2). 


$$
\begin{aligned}
& \mathrm{Ag}_{\mathrm{La}}^{\prime \prime}+\mathrm{M}_{\mathrm{M}}^{\bullet}+\mathrm{O}_{\mathrm{O}}^{\mathrm{x}}+\mathrm{H}_{2}(\mathrm{~g}) \rightarrow \mathrm{v}_{\mathrm{La}}^{\prime \prime \prime}+\mathrm{Ag}(\mathrm{s})+\mathrm{M}_{\mathrm{M}}^{\mathrm{x}}+\mathrm{v}_{\mathrm{O}}^{\bullet \bullet}+\mathrm{H}_{2} \mathrm{O}(\mathrm{g}) \\
& (\mathrm{M}=\mathrm{Fe} \text { or } \mathrm{Mn}) \\
& 2 \mathrm{Ag}_{\mathrm{La}}^{\prime \prime}+\mathrm{O}_{\mathrm{O}}^{\mathrm{x}}+\mathrm{H}_{2}(\mathrm{~g}) \rightarrow 2 \mathrm{v}_{\mathrm{La}}^{\prime \prime \prime}+\mathrm{v}_{\mathrm{O}}^{\bullet \bullet}+2 \mathrm{Ag}(\mathrm{s})+\mathrm{H}_{2} \mathrm{O}(\mathrm{g})
\end{aligned}
$$

Referring to these defect equilibria, either transition metal ions on the B-site of the $\mathrm{La}(\mathrm{III}) \mathrm{M}(\mathrm{III}) \mathrm{O}_{3}$ perovskite are involved in the Ag exsolution process and oxidized as in reaction (1) or not as in reaction Eq. (2) depending on the transition metal, M. When exsolution of $\mathrm{Ag}$ is triggered from the lanthanum-perovskite, the conductivity increases which can be attributed to the metallic Ag nanoparticles increasing the total electrical conductivity. The Ag-dopant turns into a noble Ag metal with excellent metallic electrical conductivity [17]. The LSF and LSM materials are well known to be good electronic conductors $[18,19]$. Therefore the contribution of both materials, metal and perovskite, enhances total electrical conductivity of the composite.

In addition, according to the following oxidation defect equilibria (3) of the materials due to initial non-stoichiometry,

$$
\mathrm{O}_{2}(\mathrm{~g})+2 \mathrm{v}_{\mathrm{O}}^{\bullet \bullet} \rightarrow 2 \mathrm{O}_{\mathrm{O}}^{\mathrm{x}}+4 \mathrm{~h}^{\bullet}
$$

the enhancement of the conductivity before and after exsolution in Ag-doped LSAF and LSAM materials compared to Ag-undoped LSF and LSM can be described by the higher concentration of holes, $\mathrm{h}^{\bullet}$, as shown in reaction (3) due to higher concentration of holes, $\mathrm{v}_{\mathrm{O}}^{\bullet \bullet}$, as shown in Ag-doping reaction (4),

$$
2 \mathrm{La}_{\mathrm{La}}^{\mathrm{x}}+2 \mathrm{O}_{\mathrm{O}}^{\mathrm{x}} \stackrel{\mathrm{Ag}_{2} \mathrm{O}}{\longrightarrow} 2 \mathrm{Ag}_{\mathrm{La}}^{\prime \prime}+2 \mathrm{v}_{\mathrm{O}}^{\bullet \bullet}+\mathrm{La}_{2} \mathrm{O}_{3}(\mathrm{~s})(4)
$$

This reaction could be supplemented by the reactions (5) and (6).

$$
\begin{aligned}
& 2 \mathrm{La}_{\mathrm{La}}^{\mathrm{x}}+2 \mathrm{O}_{\mathrm{O}}^{\mathrm{x}}+2 \mathrm{M}_{\mathrm{M}}^{\mathrm{x}} \stackrel{\mathrm{Ag}_{2} \mathrm{O}}{\longrightarrow} 2 \mathrm{Ag}_{\mathrm{La}}^{\prime \prime}+2 \mathrm{M}_{\mathrm{M}}^{\bullet}+\mathrm{v}_{\mathrm{O}}^{\bullet \bullet}+\mathrm{La}_{2} \mathrm{O}_{3}(\mathrm{~s}) \\
& (\mathrm{M}=\mathrm{Fe} \text { or } \mathrm{Mn}) \\
& 2 \mathrm{La}_{\mathrm{La}}^{\mathrm{x}}+2 \mathrm{O}_{\mathrm{O}}^{\mathrm{x}} \stackrel{\mathrm{Ag}_{2} \mathrm{O}}{\longrightarrow} 2 \mathrm{Ag}_{\mathrm{La}}^{\prime \prime}+\mathrm{v}_{\mathrm{O}}^{\bullet \bullet}+2 \mathrm{~h}^{\bullet}+\mathrm{La}_{2} \mathrm{O}_{3}(\mathrm{~s})
\end{aligned}
$$

The electrical conductivity of the lanthanum-based materials increases with Ag-doping. This can be explained by the reactions (5) and (6) which picture the formation of $\mathrm{M}_{\mathrm{M}}^{\bullet}(\mathrm{M}=\mathrm{Fe}$ or $\mathrm{Mn})$ species or possibly holes as well. According to reaction (3), electron holes $\left(h^{\bullet}\right)$ are induced in the materials additionally explaining the enhanced conductivity and lower activation energy at temperatures above $400{ }^{\circ} \mathrm{C}$ (see Table 3). Regarding the Ag exsolution time, the most of the metallic Ag nanoparticles form in $\sim 10-20$ $\mathrm{h}$ depending on the exsolution temperature and further it is a very slow process (Fig. 6b) due to the limit of the Ag-doping level in the initial single phase perovskites.

The conductivity increases as a function of temperature and follows the mechanism of a small polaron hopping as can be estimated by Eq. (7),

$$
\sigma=A / k T^{v} \exp \left(-E_{a} / k T\right)
$$

where, $A$ is a material constant, $k$ is Boltzmann's constant, and $E_{a}$ is the activation energy for the total electrical conductivity. The exponent $v$ is 1 for the adiabatic small polaron hopping process, and $3 / 2$ for the non-adiabatic small polaron hopping process. The experimental results and linear fitting revealed two distinct regions in the Arrhenius-type plots for LSAF with a break-point at $\sim 400{ }^{\circ} \mathrm{C}$ (see Figs. 4 and 5 and Table 2). These two regions disclosed the different activation energies of the conduction process as given in Table 2. The higher activation energy at lower than $400{ }^{\circ} \mathrm{C}$ temperatures could be understood by higher concentration of ionic defects instead of electronic as represented by reaction (2) compared to reaction (1). The activation energies of undoped and phase pure Ag-doped lanthanum ferrites or manganites are almost same, what brings a conclusion that the materials are of the same nature and the conduction mechanism is 
the same. The composite LSAFex material with exsoluted Ag nanoparticles has higher activation energy especially in the low temperature region. The later could be explained by $\mathrm{Ag}$ particles being oxidized to silver oxide $\left(\mathrm{Ag}_{2} \mathrm{O}\right)$ at low temperatures $(<$ $200^{\circ} \mathrm{C}$ ) which is a bad electronic conductor [20]. The oxide blocks the conductivity of the material, however is kinetically unstable at elevated temperatures exceeding $200{ }^{\circ} \mathrm{C}$ [21]. On the other hand, undoped LSM and Ag-doped LSAM materials exhibit close activation energy values and no break-point in the whole temperature region. The activation energies in the LSM-based materials are decreasing in the following order LSM > LSAM > LSAMx, and reveal the composites to be the best electrical conductors. The differences between LSF- and LSM-based materials can be explained by the sensitivity of the materials to the charge carrier mobility at different temperature.

The Ag exsolution in LSAF materials at high temperatures $\left(500^{\circ} \mathrm{C}\right)$ seems to proceed fast in $<10 \mathrm{~h}$ with the following slight decrease in conductivity (see Figs. $6 \mathrm{~b}$ and $6 \mathrm{c}$ ). The later could be explained by the stability of LSAF material in $5 \% \mathrm{H}_{2} / \mathrm{N}_{2}$. The effect of reducing atmosphere and electric field in LSAF materials is suggested in the following defect equilibria (8) and (9).

$$
2 \mathrm{Fe}_{\mathrm{Fe}}^{\bullet}+\mathrm{O}_{\mathrm{O}}^{\mathrm{x}}+\mathrm{H}_{2}(\mathrm{~g}) \rightarrow 2 \mathrm{Fe}_{\mathrm{Fe}}^{\mathrm{x}}+\mathrm{v}_{\mathrm{O}}^{\bullet \bullet}+\mathrm{H}_{2} \mathrm{O}(\mathrm{g})(8)
$$

In order to explain the phenomenon at $500{ }^{\circ} \mathrm{C}$, one has to evaluate both competing processes as shown in reactions (1) and (2) first. Since the electrical conductivity is increasing in the beginning, the reactions (1) and (2) are dominating due to metallic $\mathrm{Ag}$ in the materials. After the Ag exsolution is finished, reaction (8) dominates for some time. When all the initially oxidized $\mathrm{Fe}$ is reduced, the slight increase in the conductivity occurs probably due to the change in the charge carrier path or velocity. Notably, the compositional changes and degradation of the LSAM materials in reducing $5 \% \mathrm{H}_{2} / \mathrm{N}_{2}$ atmosphere occur only at $>550{ }^{\circ} \mathrm{C}$ as was discussed elsewhere [14].

The results of this study reveal that the undoped and Ag-doped lanthanum-based perovskites are stable towards both oxidizing and reducing atmospheres at elevated temperatures up to $500{ }^{\circ} \mathrm{C}$ and the reducing atmosphere does not degrade the materials below $500{ }^{\circ} \mathrm{C}$. At higher temperatures and reducing atmosphere, one would doubt the relevance of the Ag-doped LSF materials for the application as e.g. fuel electrodes in solid oxide cells due to possible reduction of $\mathrm{Fe}$ as shown in the reaction (8) and further reduction and decomposition of the perovskite. On the other hand, Fig. 3 reveals the single-phase LSAF materials to be stable in air what implies the potential for applications as oxygen electrode in solid oxide cells. The XRD and SEM measurement results of the LSAF after conductivity test in $5 \% \mathrm{H}_{2} / \mathrm{N}_{2}$ at $420{ }^{\circ} \mathrm{C}$ are emphasized in Fig. 7. The cell parameters and the quality of the refinement highlight that the orthorhombic Pbnm phase of the perovskite is maintained after reducing conditions at $420{ }^{\circ} \mathrm{C}$ and prolonged time. The only secondary phase in the host perovskite is metallic $\mathrm{Ag}$ after exsolution. It is important to note that any residues of metallic Fe or its oxides were not detected during both, XRD and SEM/EDS measurements. Referring to Fig. 6 and stability of the materials in reducing atmosphere, the values of conductivity show quite systematic trend with respect to temperature and time. Higher temperature and prolonged exsolution time enhance electrical conductivity of the materials. However, it can be seen that the conductivity of LSAM material at $420{ }^{\circ} \mathrm{C}$ is increasing in time up to some specific point after which the conductivity decreases slightly back (Figs. 6b and 6c). This could be attributed to the change of velocity of the charge carriers. In addition, no intercalation of $\mathrm{Ag}$ backwards to the lattice after exsolution in $5 \% \mathrm{H}_{2} / \mathrm{N}_{2}$ and measurements in air was observed as discussed in some literature [22]. The exsoluted Ag metal even on the nanoscale is stable 
embedded outside the perovskite lattice in metallic form instead of inside in ionic form.

According to the results in Fig. 6d and Table 4 representing the dependence of DC electrical conductivity on $\mathrm{Ag}$ exsolution time in LSAF material measured in $5 \% \mathrm{H}_{2} / \mathrm{N}_{2}$ at $420{ }^{\circ} \mathrm{C}$, the empirical mathematical functions can be applied and the experimental results fitted. The best result is achieved by exponential fitting with the equation given in Fig. $6 \mathrm{~d}$. If one assumes that the increasing conductivity at $420{ }^{\circ} \mathrm{C}$ is associated with the concentration of the charge carriers in time by exsolution of $\mathrm{Ag}$ nanoparticles from the perovskite lattice, the fitting results can be summarized as the following Eq. (9),

$$
\sigma_{420}=114.9-97.7 \exp (-0.2 t)
$$

where, $\sigma$ is measured in $\mathrm{S} \cdot \mathrm{cm}^{-1}$ and $t$ is in h. By analyzing the Eq. (9), it can be seen that the maximum conductivity value at the used conditions is 114.9 $\mathrm{S} \cdot \mathrm{cm}^{-1}$. On the other hand, just before the exsolution starts at $420{ }^{\circ} \mathrm{C}$ the materials have electrical conductivity of $17.2 \mathrm{~S} \cdot \mathrm{cm}^{-1}$ in reducing atmosphere of $5 \% \mathrm{H}_{2} / \mathrm{N}_{2}$.

\section{Conclusion}

The phase pure $\mathrm{La}_{0.85-x} \mathrm{Sr}_{0.15} \mathrm{Ag}_{x} \mathrm{FeO}_{3-\delta}$ and $\mathrm{La}_{0.85-x} \mathrm{Sr}_{0.15} \mathrm{Ag}_{x} \mathrm{MnO}_{3-\delta}(x=0-0.05)$ materials were synthesized and the time effect of silver exsolution on the electrical conductivity was studied. The materials revealed good stability of the single phase in air and reducing atmosphere of $5 \% \mathrm{H}_{2} / \mathrm{N}_{2}$. The formation of $\mathrm{Ag}$ nanoparticles on the surface after a reductive heat treatment at $420{ }^{\circ} \mathrm{C}$ in $5 \% \mathrm{H}_{2} / \mathrm{N}_{2}$ was confirmed. The lattice expansion was detected with $\mathrm{Ag}$-doping and the contraction was observed after $\mathrm{Ag}$ exsolution from single phase perovskite. The electrical conductivity of undoped and Ag-doped LSF and LSM reached 80-230 $\mathrm{S} \cdot \mathrm{cm}^{-1}$ at $800{ }^{\circ} \mathrm{C}$ in air. It was found that the electrical conductivity increased in Ag-doped materials and in composites after $\mathrm{Ag}$ exsolution compared to Ag-undoped perovskites. The electrical conductivity increased in the materials with prolonged exsolution time in reducing $5 \% \quad \mathrm{H}_{2} / \mathrm{N}_{2}$. The Ag-modified perovskites showed good operational stability in reducing atmosphere referring to increasing conductivity below $500{ }^{\circ} \mathrm{C}$ in $5 \% \mathrm{H}_{2} / \mathrm{N}_{2}$. Our results indicate that Ag-nanoparticle decorated LSF and LSM composites are potential SOFC cathode materials for the oxygen reduction reaction.

\section{Acknowledgements}

Rokas Sažinas (RS) as the main author would like to acknowledge financial support from Villum Foundation for the research activities performed at DTU Energy. RS would also like to acknowledge DTU Energy technicians and employees Jens Østergaard, Jens F. S. Borchsenius, Ebtisam Abdellahi, Annelise Mikkelsen for the qualified technical support during the experiments.

\section{References}

[1] Hansen, K. K. 2014. "Electrochemical Reduction of Oxygen and Nitric Oxide at Low Temperature on $\mathrm{La}_{1-x} \mathrm{Sr}_{x} \mathrm{FeO}_{3-\delta}$ Cathodes." Electrocatalysis 5: 256-61.

[2] Fan, L., Zhu, B., Su, P.-C., and He, C. 2018. "Nanomaterials and Technologies for Low Temperature Solid Oxide Fuel Cells: Recent Advances, Challenges and Opportunities." Nano Energy 45: 148-76.

[3] Sun, Y., Li, J., Zeng, Y., Amirkhiz, B. S., Wang, M., et al. 2015. "A-Site Deficient Perovskite: the Parent for in Situ Exsolution of Highly Active, Regenerable Nano-Particles as SOFC Anodes." J. Mater. Chem. A 3: 11048-56.

[4] Sun, Y. F., Zhang, Y. Q., Chen, J., Li, J. H., Zhu, Y. T., et al. 2016. "New Opportunity for in Situ Exsolution of Metallic Nanoparticles on Perovskite Parent." Nano Lett. 16: 5303-9.

[5] Liu, S., Liu, Q., and Luo, J.-L. 2016. "Highly Stable and Efficient Catalyst with in Situ Exsolved Fe-Ni Alloy Nanospheres Socketed on an Oxygen Deficient Perovskite for Direct $\mathrm{CO}_{2}$ Electrolysis." ACS Catalysis 6: 6219-28.

[6] Tanaka, H., Taniguchi, M., Uenishi, M., Kajita, N., Tan, I., et al. 2006. "Self-regenerating Rh- and Pt-based Perovskite Catalysts for Automotive-Emissions Control." Angew Chem Int Ed Engl 45: 5998-6002.

[7] Nishihata, Y., Mizuki, J., Akao, T., Tanaka, H., Uenishi, M., et al. 2002. "Self-regeneration of a Pd-perovskite Catalyst for Automotive Emissions Control." Nature 418: 
164-7.

[8] Gao, Y., Lu, Z., You, T. L., Wang, J., Xie, L., et al. 2018. "Energetics of Nanoparticle Exsolution from Perovskite Oxides." J. Phys. Chem. Lett. 9: 3772-8.

[9] Neagu, D., Papaioannou, E. I., Ramli, W. K. W., Miller, D. N., Murdoch, B. J., et al. 2017. "Demonstration of Chemistry at a Point through Restructuring and Catalytic Activation at Anchored Nanoparticles." Nature Communications 8: 1855.

[10] Thommy, L., Joubert, O., Hamon, J., and Caldes, M.-T. 2016. "Impregnation versus Exsolution: Using Metal Catalysts to Improve Electrocatalytic Properties of LSCM-based Anodes Operating at $600{ }^{\circ} \mathrm{C} . "$ Int. J. Hydrogen Energy 41: 14207-16.

[11] Irvine, J. T. S., Neagu, D., Verbraeken, M. C., Chatzichristodoulou, C., Graves, C., and Mogensen, M. B. 2016. "Evolution of the Electrochemical Interface in High-Temperature Fuel Cells and Electrolysers." Nature Energy 1: 15014.

[12] Myung, J. H., Neagu, D., Miller, D. N., and Irvine, J. T. 2016. "Switching on Electrocatalytic Activity in Solid Oxide Cells." Nature 537: 528-31.

[13] Neagu, D., Tsekouras, G., Miller, D. N., Menard, H., and Irvine, J. T. 2013. "In Situ Growth of Nanoparticles through Control of Non-stoichiometry." Nature Chemistry 5: 916-23.

[14] Sažinas, R., Andersen, K. B., Simonsen, S. B., Holtappels, P., and Hansen, K. K. 2019. "Silver Modified Cathodes for Solid Oxide Fuel Cells." J. Electrochem. Soc. 166:
F79-88.

[15] Ricote, S., Caboche, G., Estournes, C., and Bonanos, N. 2008. "Synthesis, Sintering, and Electrical Properties of $\mathrm{BaCe}_{0.9-x} \mathrm{Zr}_{x} \mathrm{Y}_{0.1} \mathrm{O}_{3-\delta}$." J. Nanomater. 2008: 1-5.

[16] Zulfequar, M., and Kumar, A. 1986. "Effect of Porosity on Electrical Conductivity of Hot Pressed AlN Ceramic." Revue de Physique Appliquée 21: 525-9.

[17] Matula, R. A. 1979. "Electrical Resistivity of Copper, Gold, Palladium, and Silver." J. Phys. Chem. Ref. Data 8: 1147-298.

[18] Bayraktar, D., Diethelm, S., Graule, T., Van Herle, J., and Holtappels, P. 2008. "Properties of B-Site Substituted $\mathrm{La}_{0.5} \mathrm{Sr}_{0.5} \mathrm{FeO}_{3-\delta}$ Perovskites for Application in Oxygen Separation Membranes." J. Electroceram. 22: 55-60.

[19] Moriche, R., Marrero-López, D., Gotor, F. J., and Sayagués, M. J. 2014. "Chemical and Electrical Properties of LSM Cathodes Prepared by mechanosynthesis." J. Pow. Sour. 252: 43-50.

[20] Talukdar, M. I., and Baker, E. H. 1969. "Conductivity Studies on Silver Oxide." Solid State Comm 7: 309-10.

[21] Hosseinpour-Mashkani, S. M., and Ramezani, M. 2014. "Silver and Silver Oxide Nanoparticles: Synthesis and Characterization by Thermal Decomposition." Mater. Lett. 130: 259-62.

[22] Zhou, W., Shao, Z., Liang, F., Chen, Z.-G., Zhu, Z., et al. 2011. "A New Cathode for Solid Oxide Fuel Cells Capable of in Situ Electrochemical Regeneration." J. Mater. Chem. 21: 15343. 